Article

\title{
Guess What ... ?-How Guessed Norms Nudge Climate-Friendly Food Choices in Real-Life Settings
}

\author{
Amelie Griesoph ${ }^{1, *}$, Stefan Hoffmann ${ }^{1}\left(\mathbb{D}\right.$, Christine Merk $^{2}$, Katrin Rehdanz $^{3}\left(\mathbb{C}\right.$ and Ulrich Schmidt ${ }^{2,4,5}$ \\ 1 Department of Marketing, Faculty of Business, Economics and Social Sciences, \\ Christian-Albrechts-Universität zu Kiel, Westring 425, 24118 Kiel, Germany; stefan.hoffmann@bwl.uni-kiel.de \\ 2 Kiel Institute for the World Economy, Kiellinie 66, 24105 Kiel, Germany; Christine.Merk@ifw-kiel.de (C.M.); \\ Ulrich.Schmidt@ifw-kiel.de (U.S.) \\ 3 Department of Environmental and Energy Economics, Faculty of Business, Economics and Social Sciences, \\ Christian-Albrechts-Universität zu Kiel, Wilhelm-Seelig-Platz 1, 24118 Kiel, Germany; \\ rehdanz@economics.uni-kiel.de \\ 4 Department of Economics, Faculty of Business, Economics and Social Sciences, \\ Christian-Albrechts-Universität zu Kiel, Wilhelm-Seelig-Platz 1, 24118 Kiel, Germany \\ 5 Department of Economics and Econometrics, University of Johannesburg, Auckland Park 2006, \\ Johannesburg 2092, South Africa \\ * Correspondence: griesoph@bwl.uni-kiel.de
}

Citation: Griesoph, A.; Hoffmann, S.; Merk, C.; Rehdanz, K.; Schmidt, U.

Guess What ... ?-How Guessed

Norms Nudge Climate-Friendly Food Choices in Real-Life Settings.

Sustainability 2021, 13, 8669.

https: / doi.org/10.3390/su13158669

Academic Editor: Grigorios

L. Kyriakopoulos

Received: 6 July 2021

Accepted: 1 August 2021

Published: 3 August 2021

Publisher's Note: MDPI stays neutral with regard to jurisdictional claims in published maps and institutional affiliations.

Copyright: (c) 2021 by the authors. Licensee MDPI, Basel, Switzerland. This article is an open access article distributed under the terms and conditions of the Creative Commons Attribution (CC BY) license (https:// creativecommons.org/licenses/by/ $4.0 /)$.
Abstract: Social norms, also called social comparison nudges, have been shown to be particularly effective in promoting healthy food choices and environmentally friendly behaviors. However, there is limited evidence on the effectiveness of these nudges for promoting sustainable and climatefriendly food choices and their potential to reduce greenhouse gas emissions and support the related SDGs. The paper reports a field experiment that tests the effectiveness of two social norms in a reallife setting based on revealed preferences. The study distinguishes between the widely researched descriptive norms and guessed norms, the latter being tested in this context for the first time. While descriptive norms communicate typical patterns of behavior (e.g., $50 \%$ of canteen visitors choose vegetarian meals), guessed norms are determined by the individual's best guess about the norm in a specific context. The results confirm a remarkable nudging effect of guessed norms: The higher the presumed proportion of vegetarian dishes sold, the lower the probability of choosing a vegetarian dish. Surprisingly, this effect is independent of the respective norm specification (meat or vegetarian norm). The paper provides advice for policy makers about when and how to use guessed norms.

Keywords: climate-friendly behavior; field experiment; guessed norm; nudging; social norms

\section{Introduction}

The current agriculture and food production are among the most significant drivers of greenhouse gas emissions (GHG) as well as biodiversity loss, pollution, land use change, and the depletion of freshwater resources [1-4]. Animal husbandry is the source of about $14.5 \%$ of global GHG emissions [5], a figure that is even higher than the emissions of the global transport sector and that is expected to rise steeply in the future due to population growth and increasing per capita meat consumption [5]. Without changes in production technologies and consumption patterns, the environmental impacts of food production could increase by $50-90 \%$ between 2010 and 2050 [1].

A number of studies have shown that shifting human diets towards the reduced consumption of meat and dairy products holds significant GHG mitigation potential [6-9]. For example, cutting the consumption of animal products could reduce food-based emissions by almost $50 \%$ compared to a standard diet [10]. The EAT-Lancet Commission estimated that annual global GHG emissions would decrease between 4.8 and $7.7 \mathrm{Gt} \mathrm{CO}_{2}$ if a healthy reference diet that includes low amounts of meat or a vegan diet, respectively, were adopted compared to a business-as-usual scenario $\left(9.8 \mathrm{Gt} \mathrm{CO}_{2}\right)$ [11]. Shifting affluent/Western diets 
towards more plant-based nutrition would also lower the pressure on land use [7,11], the need for nitrogen [9], and phosphorous application and the use of water [12]; furthermore, it would improve health outcomes including lower risks of coronary heart disease, strokes, and cancer [13-15]. Besides the positive effect on Sustainable Development Goal 13 (SDG 13; climate action) other SDGs such as zero hunger (SDG 14), clean water and sanitation (SDG 6), responsible consumption and production (SDG 12), life on land (SDG 15) and life below water (SDG 14) would benefit [13].

Since consuming meat is an individual and free choice, encouraging behavioral changes toward a meat-reduced or even meat-free diet is crucial for GHG mitigation and for supporting these SDGs. In general, there are several approaches to alter consumers' eating behavior. However, introducing emissions taxes on food or bans is politically difficult [16]. Also, consumers are often unaware of the link between the consumption of animal products and climate change (e.g., [17]). Therefore, the call for softer and politically less controversial measures, such as nudging, is becoming louder. Nudging attempts to influence consumers' behavior in a predictable way without using bans, regulations, taxes, or other economic incentives [18]. While there are various nudging tools, the use of social norms, also called social comparison nudges, has proven particularly effective in promoting healthy food choices or environmentally friendly behaviors (e.g., [19-25]). There is limited evidence, however, on the effectiveness of nudges, including social norms, on sustainable and climate-friendly food choices (e.g., [26-29]) and further research is crucially needed.

This paper adds to the literature in several ways. First, studies on the effectiveness of social norms on sustainable or climate-friendly food choices often rely on stated preferences. We test the effectiveness of multiple social norms in a real-life setting based on revealed preferences conducting a field experiment in university canteens. Second, extant studies do not differentiate between different types of social norms for nudging climate-friendly consumption. We differentiate between two types of social norms, descriptive norms and guessed norms. While descriptive norms communicate typical patterns of behavior (e.g., $50 \%$ of the canteen visitors choose vegetarian meals), guessed norms are determined by the individual and vary between individuals. Third, although there is research about climate-friendly meal choices in real-life settings that tests the effects of social influences, previous studies have primarily examined the effects of descriptive social norms [29]. We are, to our best knowledge, the first to test guessed norms in the context of sustainable, particularly climate-friendly, behavior. We expect that guessed norms exert stronger effects than descriptive norms, as they imply a higher level of norm activation. The individual must actively think about the prevailing descriptive norm and presume a typical pattern of behavior. Fourth, we are the first to investigate the effects different specifications, i.e., meat vs. vegetarian norm. In sum, this paper aims to test the potential of social norms, in particular guessed norms, to nudge climate-friendly meal choices in a real-life setting and thus the potential to reduce GHG emissions and to support related SDGs.

The remainder of the paper is organized as follows. We briefly present the theoretical background of social norms and introduce the concept of guessed norms. We then present the materials and the procedure of our field experiment. Next, we describe and discuss the results based on the field experiment's survey data. We conclude with implications for practitioners and policymakers and outline directions for future research.

\section{Theoretical Background}

\subsection{Social Norms}

Human behavior and decision making is strongly affected by the social environment [29-31]. Early research on social influence originating in sociology describes the social influences rather generally. For example, frame analysis looks at personal experiences, personal interactions, social interactions, as well social norms, rules, traditions, etc., to analyze sense making and the social constructions of reality [32,33]. Building on this early work, subsequent approaches in other disciplines focused on more fine-grained aspects and concepts $[34,35]$. Following this line of research, we explicitly focus on social 
norms which have been shown to have persuasive power in consumer behavior and decision making [36,37]. Norms are distinct from personal interactions, attitudes, or values, which can be private and do not necessarily affect behavior [38]. Social norms are the customary rules of conduct that guide behavior in groups and societies. They are in part sustained by the approval or disapproval of behavior $[39,40]$. Moreover, social norms can change and evolve over time [41].

In social psychology and behavioral economics, the effects of social norms have been studied intensively [29]. To have an impact on behavior, social norms must be salient during the decision-making process [42]. Based on this, the model of social norm activation, states that individuals must be aware of the norms in a specific social situation and must agree that the norms are relevant in this situation [43]. This is in line with empirical studies in social psychology that find stronger effects with an increasing attention to descriptive norms in the area of pro-social behavior (e.g., [44]). The model of social norm activation also accounts for individual differences in sensitivity to social norms [43].

Social norms bear a high potential to significantly affect sustainable food choice behavior, as consumers have been shown to be influenced by the presence, behaviors, and expectations of others $[36,45,46]$. Several studies considered the effect of social norms on sustainable consumer behavior in general (e.g., [37,39]). However, food choice situations are more challenging for norms than the choice situations in previous sustainability studies since food choices are habitual and multi-motive driven $[47,48]$. Although several studies have looked at the influence of social norms on healthy food choices (e.g., [49-51]), it is not clear whether these findings would also apply to sustainable or climate-friendly food choices. The norm is different to other food studies, because the norm does not focus on healthy food choices where the consequences center on the individual, but sustainable food choices where the consequences center on society [51]. Therefore, norms might be less effective in nudging sustainable eating compared to healthy eating. Empirical studies confirmed that norms for environmental behavior may have different and distinct effects because personal and collective interests may conflict [52,53].

In sum, social norms for changing eating behavior must overcome various barriers to have an impact [51]. The effects of social norms might be highly context dependent. Therefore, such interventions must be tested directly in the context of interest, as we do in this study.

\subsubsection{Descriptive Norms}

According to the focus theory of normative conduct, individuals' behavior is guided by two types of social norms-descriptive and injunctive norms [54,55]. Each refers to a different aspect of information about behavior and consequently triggers different sources of human motivation. Descriptive norms refer to how people behave (the norms of is). As such, this type of social norm is collectively defined by the aggregation of actual behaviors, which then serves as a social proof to guide behavior. In contrast, injunctive norms (the norms of ought) refer to how people should behave [54-56]. The distinction between descriptive and injunctive norms is by far the most prominent and widely tested one. Both types of social norms affect consumer behavior. The consumer behavior literature has particularly reported effects of descriptive norms and we therefore rely on this type of norm $[37,54,57,58]$.

\subsubsection{Guessed Norms}

In contrast to descriptive norms, guessed norms have largely been neglected in nudging studies as well as in studies on sustainable or climate-friendly behavior. We define guessed norms as inter-individually variable guesses of a certain descriptive norm. Guessed norms are based on the individuals' beliefs and assumptions. They thus vary depending on the person's assumptions about the general behavioral patterns. Guessing the norm implies a higher level of norm activation in comparison to just being informed about 
the descriptive norm, because the individual has to actively think about the prevailing descriptive norm.

Guessed norms have been studied in the field of pro-social behavior $[59,60]$. One study tested whether guessed norms evoke a higher level of norm activation in the context of pro-social behavior [59]. The results indicate that individuals that made a guess about peer behavior increased their pro-social behavior. This effect was due to their increased attention to the norm even though no descriptive norm was provided. Another study came to a similar conclusion [60]. Asking for a guess of the descriptive norm significantly increased donations compared to just providing the descriptive norm.

Following up on this, we compare the effect of guessed norms and descriptive norms on climate-friendly meal choices. To the best of our knowledge, the effects of guessed norms have not yet been tested with regard to climate-friendly meal choices. We expect participants that must guess the descriptive norm to be more attentive than participants that are only informed about the descriptive norm. Hence, our first hypothesis is:

Hypothesis H1. Guessed norms evoke more positive nudging effects on meal choices than descriptive norms.

\subsection{Level of the Norm Specification}

Previous research about descriptive and guessed norms has mainly focused on so called majority norms, i.e., most people's behavior (e.g., [37,39]). In contrast, minority norms describe what fewer people do. Majority norms indicate the typical behavior in a certain situation by referring to how most people behave and thus provide consensus information [61]. According to the theories of normative social influence and conformity $[62,63]$, descriptive majority norms are very powerful because they provide information about the predominant behavior, a standard norm, from which people do not want to diverge as they seek social approval and try to avoid disapproval [64]. Therefore, there is a strong incentive to use majority statements that imply a higher level of compliance. The most prominent study on descriptive norms relates to the reuse of hotel towels [37]. The communication of the norm "Almost 75\% of guests who are asked to participate in our new resource savings program do help by using their towels more than once" in a treatment group of hotel rooms yielded in a significantly higher towel reuse rate in comparison to a standard environmental protection condition ([37], p. 474). However, studies on descriptive majority norms often rely on assertions or factually inaccurate information and consequently raise ethical concerns. Using unverifiable or false assertions might be an acceptable manipulation in lab experimental settings but is problematic in real-life setting [64].

Besides various studies confirming the positive effects of majority norms, there are some negative, unwanted effects as well. For example, informing people that an unwanted behavior is common in a specific situation may lead to an increase in this behavior instead of alerting and deterring them as intended. People may even adopt the undesired behavior although they usually seldom behaved like that through the effects of normalization [65], free riding [66] or licensing [67]. For example, informing students about heavy alcohol use on campus increased their alcohol consumption instead of decreasing it [68].

In contrast to majority norms, minority norms describe the behavior of relatively few people and by implication refer to atypical or rare behavior. The body of literature on minority norms is rather limited, although minority norms are commonly used in public communication with the intention to alarm people (e.g., regarding a low engagement in health protective behavior) (e.g., [61]). Building upon social identity theory (e.g., [69]), empirical studies find that communicating minority norms reduces the positive behavior when the identification with the reference group is high compared to communicating the majority norm of negative behavior [61]. This is in line with empirical studies in the field of health-related behavior which find that the behavior of people that identify strongly with a particular group is more influenced compared to when the identification is weak [70,71]. However, little is known about the extent of the detrimental effect of minority norms and if the direction of the effects of minority and majority norms are the same for guessed 
norms. We conclude that the level of the guessed norm (majority or minority or some nuances in between) could influence the individual's meal choice. Consequently, the second hypothesis is:

Hypothesis H2. The level of the guessed norm affects vegetarian meal choices.

\subsection{Vegetarian vs. Meat Norm Specification}

The findings about majority and minority norms further raise important questions about how to design norm interventions in the area of promoting climate-friendly meal choices. While there is a widespread understanding that meat consumption has negative impacts on the environment and health, the number of people who actually eat meatfree or meat-reduced on a daily basis may be rather low, suggesting a currently low norm for vegetarian consumption (e.g., $[9,14])$. Many people will therefore consider meat consumption as the majority norm and vegetarian consumption as a minority norm, which could affect behavior. Consequently, we distinguish two norm specifications, a vegetarian and a meat norm specification, for the guessed norm as well as the descriptive norm. In the vegetarian norm specification, vegetarian meal choices are made salient and in the meat norm specification, meat meal choices are made salient. Therefore, our third hypothesis is:

Hypothesis H3. The vegetarian norm specification has a more positive effect on choosing a vegetarian meal than a meat norm specification.

\section{Materials and Methods}

\subsection{Procedure and Treatments}

We conducted a 2 (guessed vs. descriptive norm) $\times 3$ (vegetarian specification vs. meat specification vs. control group) between-subjects field experiment in university canteens in the second week of December 2019 during the lunch break from 11 a.m. to 2 p.m. on Monday, Tuesday, Thursday, and Friday. We collaborated with the canteen operator to conduct our field experiment under the guise of an operator survey.

The natural setting offers a higher degree of external validity compared to laboratory experiments [72,73]. However, the natural setting implies some restrictions with regard to the level of standardization of the experimental design. For our experiment, this means that the guessed and descriptive norm cannot be tested at the same time in the same canteen. Testing them sequentially in the same canteen (e.g., giving the descriptive norm first and asking for a guess of it at a later time) would also have biased the results. Therefore, we conducted the field experiment in different locations at the same time to avoid treatment contamination between canteens while keeping the variation between groups due to different weekdays or specific events constant.

We ran the experiment in two canteens (about 20 min walking distance from each other) on the campus of a university in a medium-sized city. Contamination between the two canteen samples can be ruled out, because the customers are students from different fields of studies that typically stick to one of the canteens (the canteens are located near the lecture rooms of the respective fields of studies). Both canteens offer three to five dishes every day. At least two dishes are the same in both canteens and there is at least one vegetarian dish per day. Beyond the common dishes, the two canteens cater to the preferences of their typical customers; one offers a higher share of vegetarian and vegan choices. To control for differences between the customer groups, there is a control group in each canteen.

The participants were randomly assigned to the treatments and the respective versions of the flyer that contained the paper and pencil questionnaire (see Appendix A). Guessed norms were tested in canteen 1, descriptive norms in canteen 2 . The questionnaires for the control groups (G1 and D1) were identical and contained questions about age, gender, and the number of canteen visits per week. The statements used for the different treatments 
are provided in Table 1 . The values for the descriptive norm (D2, D3) were taken from the canteens' actual sales data from the previous winter term.

Table 1. Vegetarian and meat norm specifications.

\begin{tabular}{|c|c|c|}
\hline & Descriptive Norm & Guessed Norm \\
\hline Control Group & No Norm Presented (D1) & No Norm to be Guessed (G1) \\
\hline Vegetarian norm & $\begin{array}{c}\text { "Did you know? On average, } 44 \% \text { of our } \\
\text { canteen customers chose a vegan or } \\
\text { vegetarian main dish during the last } \\
\text { winter term." (D2) }\end{array}$ & $\begin{array}{l}\text { "What do you think was the proportion of vegan or } \\
\text { vegetarian main dishes sold in our canteen last } \\
\text { winter term? \% of the main dishes sold during } \\
\text { the last winter term were vegan or vegetarian." (G2) }\end{array}$ \\
\hline Meat norm & $\begin{array}{c}\text { "Did you know? On average, } 56 \% \text { of our } \\
\text { canteen customers chose a main dish } \\
\text { containing meat or fish during the last } \\
\text { winter term." (D3) }\end{array}$ & $\begin{array}{l}\text { "What do you think was the proportion of meat and } \\
\text { fish main dishes sold in our canteen last winter } \\
\text { term? \% of the main dishes sold during the last } \\
\text { winter term contained meat, sausage or fish." (G3) }\end{array}$ \\
\hline
\end{tabular}

The participants were recruited in front of the entrance of the canteens (see Figure 1). They were asked to take part in a questionnaire by the canteen operator and a lottery with a chance to win a $50 €$-voucher for the canteen. Before entering the canteen, they filled in the questionnaire, then they bought their lunch. Directly behind the cash desks, we placed two ballot boxes, one for the questionnaire of the participants who had chosen a vegan/vegetarian dish and one for the questionnaires of those who had chosen a dish with meat or fish. Our research assistants monitored the correct deposition into the ballot boxes. Only participants that had actually bought lunch and put their questionnaire in the ballot box could take part in the lottery. Only they are included in our analysis.

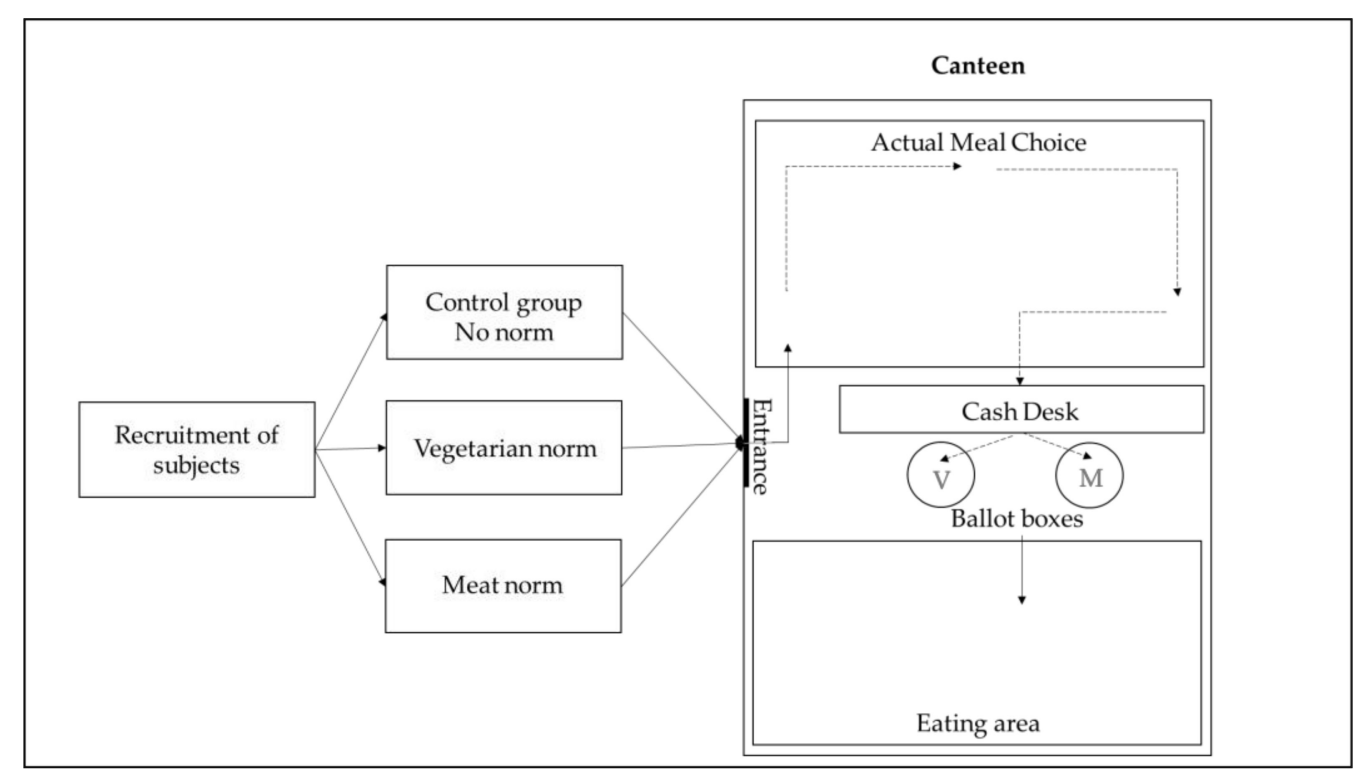

Figure 1. Setup of the experiment on site (from recruitment in front of the canteen to the ballot boxes at the cash desks). Notes: $\mathrm{V}=$ vegetarian, $\mathrm{M}=$ meat.

\subsection{Sample and Data}

During the experiment, the canteens sold 13,907 main dishes. One canteen sold 8700 meals (vegetarian choices: 28\%) and the other canteen sold 5207 meals (vegetarian choices: $40 \%$ ). A total of 1174 subjects participated in the study, 513 in canteen 1 $\left(\right.$ age $_{\text {mean }}=23$; female $\left.=53 \%\right)$ and 661 in canteen $2\left(\right.$ age $_{\text {mean }}=25$; female $\left.=56 \%\right)$. Randomization into the treatments was successful in both canteens, with approximately $32-35 \%$ of participants per treatment group (see Figure 2). 


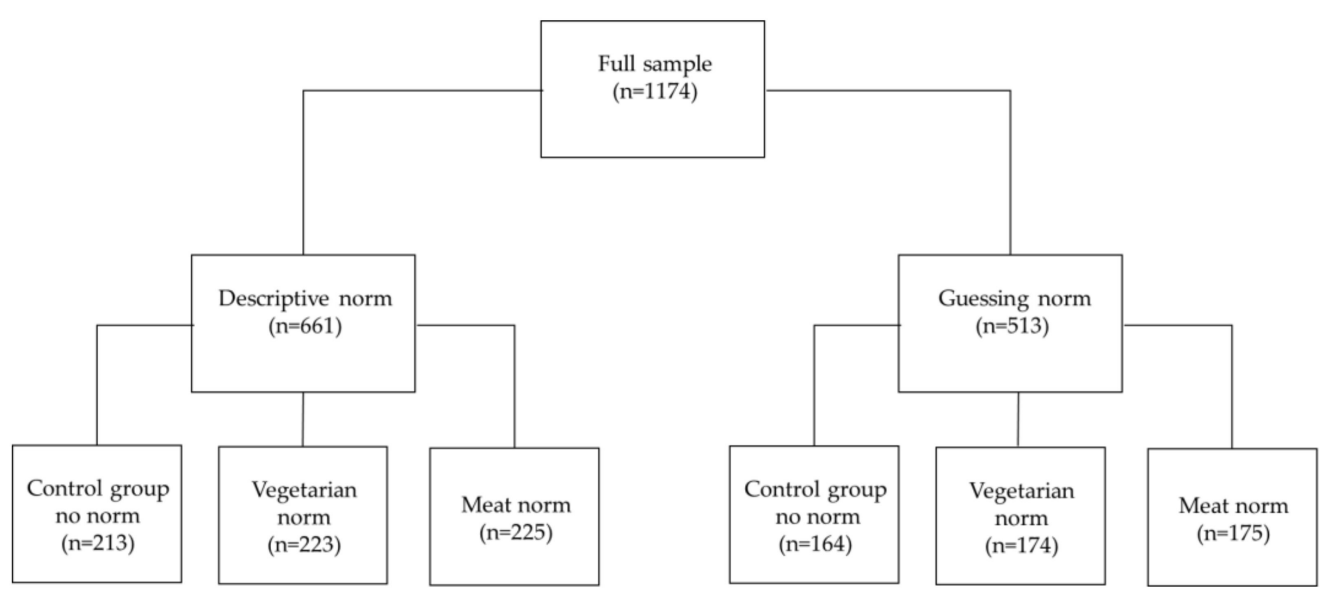

Figure 2. Number of observations per experimental group.

The share of selected vegan/vegetarian dishes was $62 \%$ in both control groups. For the meat descriptive norm and the vegetarian descriptive norm, we find a share of $57 \%$ vegan/vegetarian meal choices. Of the participants that received the meat guessed norm, $60 \%$ chose a vegan/vegetarian meal, while $64 \%$ in the vegetarian guessed norm group chose a vegan/vegetarian meal.

\subsection{Econometric Model}

We analyzed the effects of the treatments on meal choice with logistic regressions using STATA 15. The dependent variable veg takes the value 0 when the participant chose a meat or fish dish and the value 1 when she chose a vegetarian or vegan dish. The estimation of the individual probability to choose a vegetarian dish takes the following form:

$$
\operatorname{Pr}(\text { veg }=1)=F\left(\beta_{0}+\sum_{i=1}^{i=k} \beta_{i} x_{i}\right)
$$

where $F(z)=\frac{e^{z}}{\left(1+e^{z}\right)}$ is the cumulative logistic distribution; $\beta_{0}$ is the constant and the $\beta_{i}$ are the coefficients of the independent variables $x_{i} ; k$ is the number of independent variables.

Based on Equation (1), we specify three econometric models that differ in the number of independent variables. In Model 1, our base model, we control for age and gender, and include the categorial variable treatment with the category D1-descriptive control as the reference group. This means that the treatments' coefficients $\beta$ effect on the dependent variable can be interpreted as an effect compared to the reference group. In Model 2 and Model 3, we restrict the sample to those participants that had to guess the norm to analyze the effect on the level of the guesses on the probability to choose a vegetarian dish. Model 2 only includes the individual guesses as independent variable. In Model 3, we add the independent variables specified in Model 1 (age, gender, and treatment) and, in addition, the day of the observation to control for learning effects. We report regression coefficients $\beta$ and the corresponding odds ratios. The latter can be interpreted more easily. Odds ratios below 1 indicate a lower probability of choosing a vegetarian dish with a one-unit increase in the independent variable; odds ratios higher than 1 imply a higher probability with a one-unit increase keeping all other variables constant.

\section{Results}

\subsection{Effects of the Manipulation}

Table 2 shows the results of Model 1 in which vegan/vegetarian meal choices are explained by treatment groups, age, and gender. The overall model is statistically significant $\left(\mathrm{LR} \mathrm{Chi}^{2}=79.39, p=0.000\right)$. The Hosmer-Lemeshow test yields a $p$-value of 0.215 and therefore does not indicate lack of fit. We find no significant treatment effects. We only detect significant effects for the control variables age $(B=-0.020, p=0.039$, odds 
ratio $=0.980)$ and gender $(B=1.011, p=0.000$, odds ratio $=2.750)$ indicating that younger and female participants are more likely to choose a vegan/vegetarian meal.

Table 2. Results from logistic regression: Model 1.

\begin{tabular}{|c|c|c|c|c|}
\hline Explanatory Variables & B & Z-Value & $p$-Value & Odds Ratio \\
\hline Constant & 0.446 & 1.51 & 0.131 & 1.562 \\
\hline Age & -0.020 & -2.06 & 0.039 * & 0.980 \\
\hline Female & 1.012 & 8.08 & $0.000 * * *$ & 2.751 \\
\hline \multicolumn{5}{|l|}{ Treatment } \\
\hline \multicolumn{5}{|c|}{ (Reference group = D1-descriptive control) } \\
\hline ... G1-control group & 0.029 & 0.13 & 0.897 & 1.029 \\
\hline ... D2-vegetarian norm & -0.220 & -1.08 & 0.281 & 0.802 \\
\hline ... G2-vegetarian norm & 0.110 & 0.50 & 0.620 & 1.117 \\
\hline ... D3-meat norm & -0.170 & -0.84 & 0.403 & 0.844 \\
\hline ... G3-meat norm & -0.078 & -0.35 & 0.723 & 0.925 \\
\hline Pseudo $\mathrm{R}^{2}$ & 0.051 & & & \\
\hline $\mathrm{LRChi}^{2}$ & 79.39 & & $0.000 * * *$ & \\
\hline Hosmer \& Lemeshow test & 241.48 & & 0.215 & \\
\hline
\end{tabular}

Notes: Dependent variable $=$ vegan/vegetarian meal choice, ${ }^{*} p \leq 0.05,{ }^{* * *} p \leq 0.001 . \mathrm{N}=1155$.

\subsection{Effects of the Level of the Guessed Norm}

While using descriptive norms vs. guessed norms as such exerted no statistically significant effect, we now examine the effects of level of the guessed norm more closely. We find an average level of stated guesses of $62.58 \%(\mathrm{SD}=15.07)$ for the meat norm specification and $38.91 \%(\mathrm{SD}=16.73)$ for the vegetarian norm specification. This means that participants in group G2 on average guessed that 38.91\% of the main dishes sold in their canteen last winter term were vegetarian or vegan, whereas participants of group G3 on average guessed that $62.58 \%$ of the main dishes sold contained meat or fish. Surprisingly, these results are quite similar to the descriptive norms that were provided to the participants in the other canteen (vegetarian norm specification 44\% (group D2); meat norm specification $56 \%$ (group D3)). To rule out the possibility that this result is due to participants moving between canteens, we inspect the data per day (Table 3). The stated guesses are relatively constant across days, indicating that there is no interference or learning effect.

Table 3. Average level of guessed norm at different days.

\begin{tabular}{ccccccc}
\hline & \multicolumn{2}{c}{ Meat Norm Specification } & \multicolumn{2}{c}{ Vegetarian Norm Specification } \\
\cline { 2 - 6 } & Mean & SD & N & Mean & SD & N \\
\hline Day 1 & $62.77 \%$ & 12.39 & 44 & $38.93 \%$ & 16.78 & 35 \\
Day 2 & $62.69 \%$ & 16.26 & 54 & $41.55 \%$ & 19.16 & 38 \\
Day 3 & $62.07 \%$ & 16.21 & 44 & $39.20 \%$ & 15.60 & 58 \\
Day 4 & $62.85 \%$ & 15.40 & 32 & $37.32 \%$ & 16.58 & 37 \\
Total & $62.58 \%$ & 15.07 & 174 & $37.20 \%$ & 16.18 & $168 *$ \\
\hline Notes: * The number of cases is reduced by 6 subjects in this group as they did not provide a guess.
\end{tabular}

We recoded the individual guesses of the meat norm specification into vegetarian guesses (100-individual meat guesses) for further analyses which translates into almost the same average guess of vegan/vegetarian main dishes in the two groups. The participants of the meat norm specification treatment (G3) on average guessed that $37.41 \%(\mathrm{SD}=15.07)$ of the main dishes sold in their canteen were vegetarian or vegan compared to $38.91 \%$ $(\mathrm{SD}=16.73)$ in the vegetarian norm specification treatment $(\mathrm{G} 2)$. The results of the $t$-test confirm that the norm specifications of the guessed norm (vegetarian G2 vs. meat G3) had no significant influence on the participants' guesses about the sale of vegetarian dishes in the last winter term $(t=0.867, p=0.387)$. Notably, the guesses are also at a similar level as the descriptive vegetarian norm of $44 \%$ in group D2. 
We ran a logistic regression to test the effect of the level of the guessed norm on meal choices based on treatment groups G2 and G3. Table 4 shows the results of Model 2 in which vegan/vegetarian meal choices are explained by the individual guesses of the share of vegan or vegetarian main dishes sold including the recoded guesses of the share of meat dishes (see above). Model 3 contains additional control variables. The overall models are statistically significant $\left(\mathrm{LR} \mathrm{Chi}^{2}{ }_{\text {Model2 }}=4.32, \mathrm{p}_{\text {Model } 2}=0.010 ; \mathrm{LR} \mathrm{Chi}^{2}{ }_{\text {Model } 3}=35.77\right.$, p Model3 $=0.000$ ). The Hosmer-Lemeshow test yields a $p$-value of 0.139 for Model 1 and 0.219 for Model 3, suggesting that both models fit to the data well. Model 3 has a smaller AIC (420.015) than Model 2 (451.935), which indicates that this model would be preferable to Model 2.

Table 4. Results from logistic regression.

\begin{tabular}{|c|c|c|c|c|c|c|c|c|}
\hline \multirow[b]{2}{*}{ Explanatory Variable } & \multicolumn{4}{|c|}{ Model 2} & \multicolumn{4}{|c|}{ Model 3} \\
\hline & B & Z-Value & $p$-Value & $\begin{array}{l}\text { Odds } \\
\text { Ratio }\end{array}$ & B & Z-Value & $p$-Value & $\begin{array}{l}\text { Odds } \\
\text { Ratio }\end{array}$ \\
\hline Constant & 1.076 & 3.63 & $0.000^{* * *}$ & 2.933 & -1.217 & -1.46 & 0.143 & 0.296 \\
\hline $\begin{array}{l}\text { Individual guesses of veg. } \\
\text { meal choices }\end{array}$ & -0.015 & -2.07 & $0.038 *$ & 0.986 & -0.016 & -2.08 & 0.037 * & 0.984 \\
\hline $\begin{array}{l}\text { G2-Vegetarian norm } \\
\text { specification }\end{array}$ & & & & & 0.154 & 0.064 & 0.522 & 1.167 \\
\hline Age & & & & & 0.062 & 2.20 & $0.028 *$ & 1.064 \\
\hline Female & & & & & 1.23 & 5.02 & $0.000^{* * *}$ & 3.425 \\
\hline \multicolumn{9}{|l|}{$\begin{array}{l}\text { Survey Day } \\
(\text { Baseline = Day 4) }\end{array}$} \\
\hline ... Day 1 & & & & & 0.439 & 1.19 & 0.236 & 1.551 \\
\hline ... Day 2 & & & & & 0.275 & 0.80 & 0.426 & 1.317 \\
\hline ... Day 3 & & & & & 0.005 & 0.01 & 0.989 & 1.005 \\
\hline Pseudo $\mathrm{R}^{2}$ & 0.010 & & & & 0.081 & & & \\
\hline LR Chi ${ }^{2}$ & 4.32 & & $0.010^{* *}$ & & 35.77 & & $0.000^{* * *}$ & \\
\hline Hosmer \& Lemeshow test & 58.67 & & 0.139 & & 320.76 & & 0.219 & \\
\hline AIC & 451.935 & & & & 420.015 & & & \\
\hline
\end{tabular}

Notes: Dependent variable = vegan/vegetarian meal choice. ${ }^{*} p \leq 0.05,{ }^{* *} p \leq 0.01,{ }^{* * *} p \leq 0.001 . \mathrm{N}=342(\mathrm{G} 2, \mathrm{G} 3)$.

The coefficient for individual guesses of -0.015 in Model 2 indicates an expected decrease of 0.015 in the log odds of vegetarian choices for every one-unit increase of individual guesses. Note that an increase of one unit corresponds to a 1 percentage point increase in guesses. The $p$-value shows that this coefficient is significantly different from 0 $(p=0.038)$. To ease the interpretation of the 0.015 decrease in the log odds, we calculated the odds ratio, which is 0.986 . This is the expected decrease in the odds ratio for a one unit increase in the predictor variable (individual guesses), holding all other variables in the model constant.

In Model 3, we additionally control for age, gender, vegetarian norm specification (G2), and day of the survey. The variable survey day also captures the variation in menu as the share of vegan/vegetarian dishes varies across days. Just as in Model 2, we find a significant negative effect of individual guesses on the probability to choose a vegan/vegetarian meal $(B=-0.016, p=0.037$, odds ratio $=0.984)$, entailing that the higher the guessed share of vegetarian dishes sold, the lower the likelihood to choose a vegetarian dish. The norm specification itself (meat vs. vegetarian) has no significant influence $(B=0.154, p=0.522$, odds ratio $=1.167)$.

\section{Discussion}

This paper sheds light on the potential of guessed norms to nudge climate-friendly food choices in real-life settings and thus the potential to tackle climate change and support the related SDGs. While guessed norms have only been tested for pro-social behavior [59,60], we introduced guessed norms in the context of climate-friendly behavior. Specifically, we test 
the effect of guessed norms and contrast it with the effects of descriptive norms. We analyze how the level of the guessed norm affects actual food choices. Additionally, we investigate the effects of multiple specifications of these norms (via meat vs. vegetarian choices). The empirical findings add to the literature in several ways.

First, with regard to the effectiveness of nudging, this study shows once again that nudging climate-friendly meal choices is a challenging task (e.g., [30,51]). In particular, there is a growing literature that questions the effectiveness of social norms [30,51]. In line with these findings, the social comparison nudges used in the present study did not raise climate-friendly meal choices in general. Unlike former research on guessed norms which found that asking for a guess of the descriptive norm significantly increases pro-social behavior over just providing the descriptive norm $[59,60]$, we find no significant general effect of the guessed norm in the context of climate-friendly food choice.

Second, we do not find that guessing the norm exerts a generally stronger effect than descriptive norms. However, related to this, a striking finding is that the average guessed share is quite similar to the descriptive norm that was provided to the participants in the other canteen and that therefore the average effect of guessed norms should be similar to the effect of a provided descriptive norm. This effect did not occur because of the experimental setup. The mixing of treatments between canteens is highly unlikely, because students of different fields of studies typically stick to one of the canteens and the canteens are $1.5 \mathrm{~km}$ apart. Moreover, we can rule out contamination or learning effects because the guesses are relatively constant across days. Therefore, we conclude that the descriptive norm and the guessed norm are comparable. A possible substantial explanation is the wisdom of the crowd effect, which should be tested in future studies. In contrast to other studies (e.g., $[30,74,75]$ that conclude that consumers tend to overestimate, e.g., the amount of alcohol and cigarettes consumed by others and therefore adopt these undesired behaviors, our participants estimated the correct share but still engaged in the undesired behaviors.

Third, although we did not find a general effect for the guessed norms, a more indepth analysis shows that guessed norms do indeed have an effect when considered in a more nuanced way. Surprisingly, the guessed norm did not have the intended positive effect on the share of vegan/vegetarian dishes sold. On the contrary, the guessed norms lead to a backfire or boomerang effect, an effect that has been found for other measures to influence food choice as well [76]. The study reveals that the higher consumers guessed the share of vegetarian dishes sold to be, the less likely they were to choose vegetarian dishes. One explanation for this effect is psychological reactance [77]. Participants may have perceived the vegetarian norm as educational and coercive. Therefore, they intentionally select the opposite, meat-containing dish. Previous studies on injunctive norms confirm that backfire or boomerang effects can occur due to reactance behavior (e.g., [78]). Recently, an empirical study confirmed that descriptive norms can lead to backfire or boomerang effects as well [30]. However, this is the first study showing that guessed norms can also lead to backfire or boomerang effects implying psychological reactance. Another potential explanation for these results is the social moral licensing effect. This means that the climate-friendly, meat-free purchasing behavior of other canteen customers may justify the participants' own decision to consume less climate-friendly and to choose meat dishes $[67,79]$. 
Fourth, our study shows that the presentation of a norm as a meat or vegetarian norm did not influence the effect of the guessed norm. Irrespective of the norm specification (meat vs. vegetarian), guessing the norm led to the backfire or boomerang effect.

In sum, this study successfully tested guessed norms for the first time in the field of pro-environmental behavior. The results suggest that asking customers to guess the norm is not effective for promoting climate-friendly meal choices. This study once again highlights the value of field experiments, especially in the context of food choices, as small, null, or even backfiring effects for food nudging experiments are increasingly reported. Social norms must compete with other food choice motives in real-life settings which remain the main criteria in actual decision-making processes [51,72,80].

\section{Limitations and Future Research}

Like every empirical study, the present research has some limitations that should be addressed in future studies.

First, while some earlier studies support the effectiveness of social norms for different applications, such as towel re-use in hotels [37], we find no significant effect for informing about the descriptive norm. Further research should test whether attention effects might be relevant in such food choice situations. The non-significant findings might be due to inattentive reading of the questionnaire by our participants and consequently overlooking the descriptive norm. However, even if participants read the questionnaire carefully and norm activation was initiated, it may have been forgotten at the time of the purchase decision due to the special characteristics of real-life settings. Similar to supermarkets, canteens are a crowded and partly anonymous environment in which choices are shaped by high speed and the use of heuristics [30], implying an environment in which peripheral cognitive processing takes place $[30,81]$. Several studies confirm these characteristics and stress that food choices are made in less than a second $[82,83]$ with price, taste, and former choices as the paramount reasons for the decision. This may also be an explanation for the lack of a general effect of the guessed norm, despite the higher level of norm activation. Multiple nudging field experiments on the influence of injunctive norms on sustainable meal choices confirm this finding. They find small or null effects for food nudging experiments and argue that social norms have to compete with other food choice motives like price or taste, that seem crucial in real-life settings [51]. Hence, we call for more research that disentangles the attention effects and considers further food choice motives.

Second, another important limitation is the lack of explanatory variables like the general intention to reduce meat consumption as well as attitudes or knowledge about the carbon footprint of food. We limited the number of additional questions about attitudes in the present study to avoid social desirability effects. However, further studies should include additional psychographic as well as demographic characteristics.

Third, another interesting avenue for future research are the questions of how descriptive and guessed norms develop over time, what interactions exist between both in this process, and what role the two play in the development of actual behavior [29]. Incorporating frame analysis for a meta-reflexive perspective would also strengthen future research on the roles of social norms [32,33]. Scholars may further explore the role of performativity and reflexivity in the social construction of social norms. Although the psychological process of social norm activation and social norm processing has already been investigated, it has neither been studied specifically for guessed norms nor has it been examined within a framework of formalized models [29]. 


\section{Policy Recommendations}

Several policy implications as well as practical implications can be derived based on our results. The use of nudging tools is generally considered to be a cost-effective policy und marketing instrument [84]. In response, governments around the world established behavioral insights units, so called nudge units [84]. In particular, using social norms for nudging has been promoted in the literature [37]. However, despite this widespread political interest and scientific success, critical voices are recently getting louder-showing limits and failures of nudging interventions in general and the use of social norms in particular. Previous studies on injunctive (e.g., [78]) and descriptive [30] norms have already confirmed backfire or boomerang effects. This study is the first to provide evidence that guessed norms can also lead to backfire or boomerang effects. These findings show that although social norms, and especially guessed norms, are easy, low-cost alternatives that many firms and governments could implement, they have to be applied carefully [51].

This study reveals that the level of the guessed norms strongly affects the subsequent food choices. Different to descriptive norms, the consumer determines the level of the guessed norm and therefore the policy maker and/or social marketer is faced with some uncertainty. Hence, policy makers and practitioners are well advised to be aware which level of a social norm consumers assume before they decide for a guessed nudge campaign. Market research to learn about the social norm beforehand would be necessary. Moreover, a segmentation approach might be necessary to address different consumer groups differently.

Policy makers and practitioners should be aware that supposedly low-cost nudging interventions like social norms can backfire. Implying, especially in the context of sustainable consumption, renewable energy production, or negative emissions, that interventions to promote them can actually harm progress instead. Against this background, a cost-benefit assessment of environmental policy instruments is highly relevant. A repeated evaluation of instruments is therefore indispensable. And a combination of soft instruments such as nudging and hard instruments such as taxes could also be a promising approach to fast track the shift towards pro-environmental behavior.

Author Contributions: Conceptualization, A.G., S.H., C.M., K.R. and U.S.; methodology, A.G. and S.H.; validation, A.G., S.H., C.M., K.R. and U.S.; formal analysis, A.G. and S.H.; data curation, A.G.; writing—original draft preparation, A.G.; writing—review and editing A.G., S.H., C.M., K.R. and U.S.; visualization, A.G.; supervision, S.H.; project administration, A.G., S.H. and C.M.; funding acquisition, S.H., C.M., K.R. and U.S. All authors have read and agreed to the published version of the manuscript.

Funding: This research was funded by Energy and Climate Protection Corporation SchleswigHolstein-Gesellschaft für Energie und Klimaschutz Schleswig-Holstein GmbH (EKSH), project IFkE.

Institutional Review Board Statement: The study was conducted according to the guidelines of the Declaration of Helsinki and approved by the Institutional Review Board (or Ethics Committee) of Kiel University (ZEK 18/21; 5 July 2021).

Informed Consent Statement: Informed consent was obtained from all subjects involved in the study.

Data Availability Statement: Restrictions apply to the availability of these data. Data were obtained from the canteens' operator Studentenwerk Schleswig-Holstein and are not available due to privacy reasons.

Acknowledgments: The authors would like to thank the canteens' operator Studentenwerk SchleswigHolstein for making the field experiment possible and for their support during the experiment.

Conflicts of Interest: The authors declare no conflict of interest. 


\section{Appendix A}

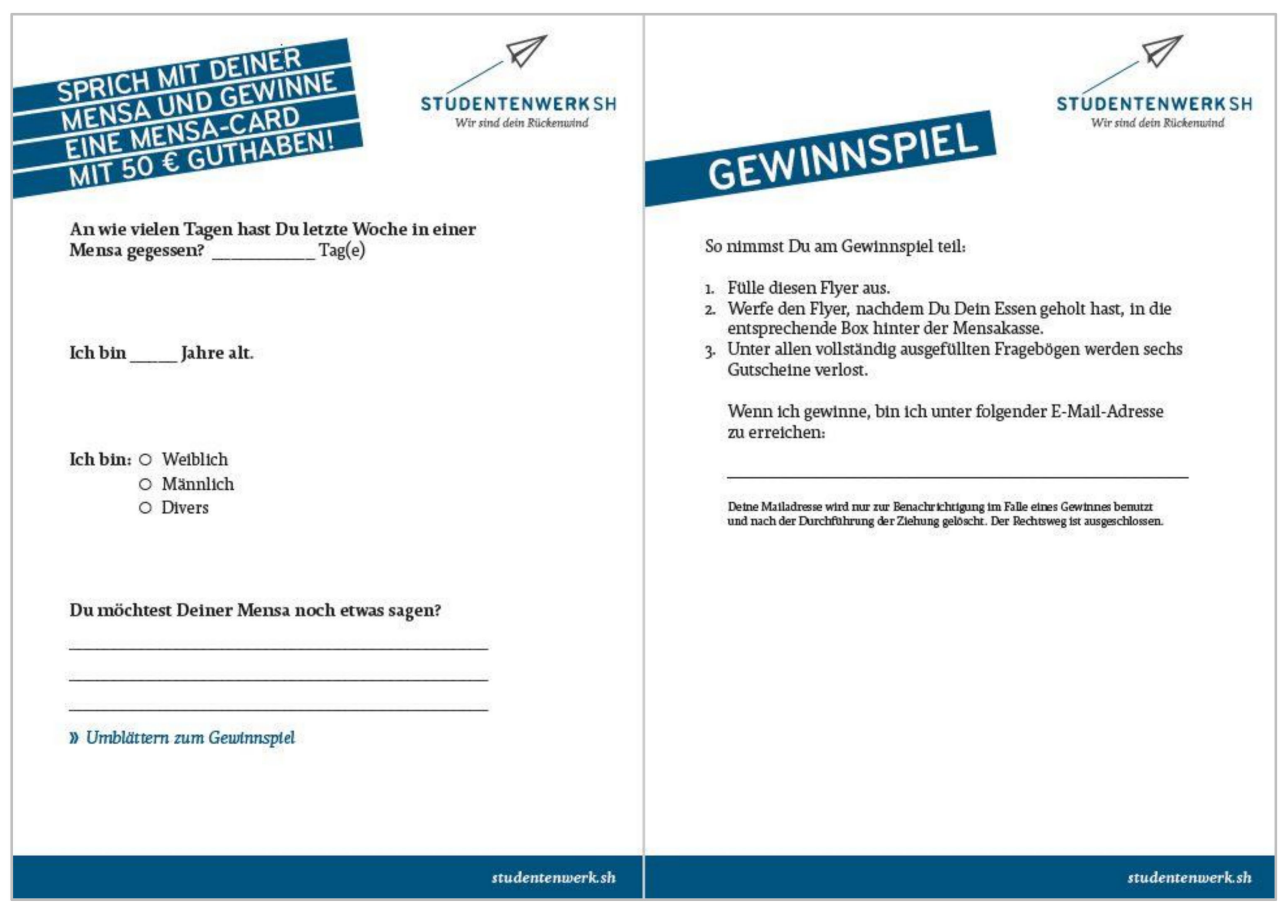

Figure A1. Flyer with questionnaire D1/G1. Left page: “Talk to your canteen and win a 50€—canteen voucher for the canteen"; followed by questions about the amount of visits last week, age, and gender. Right page: lottery instructions.

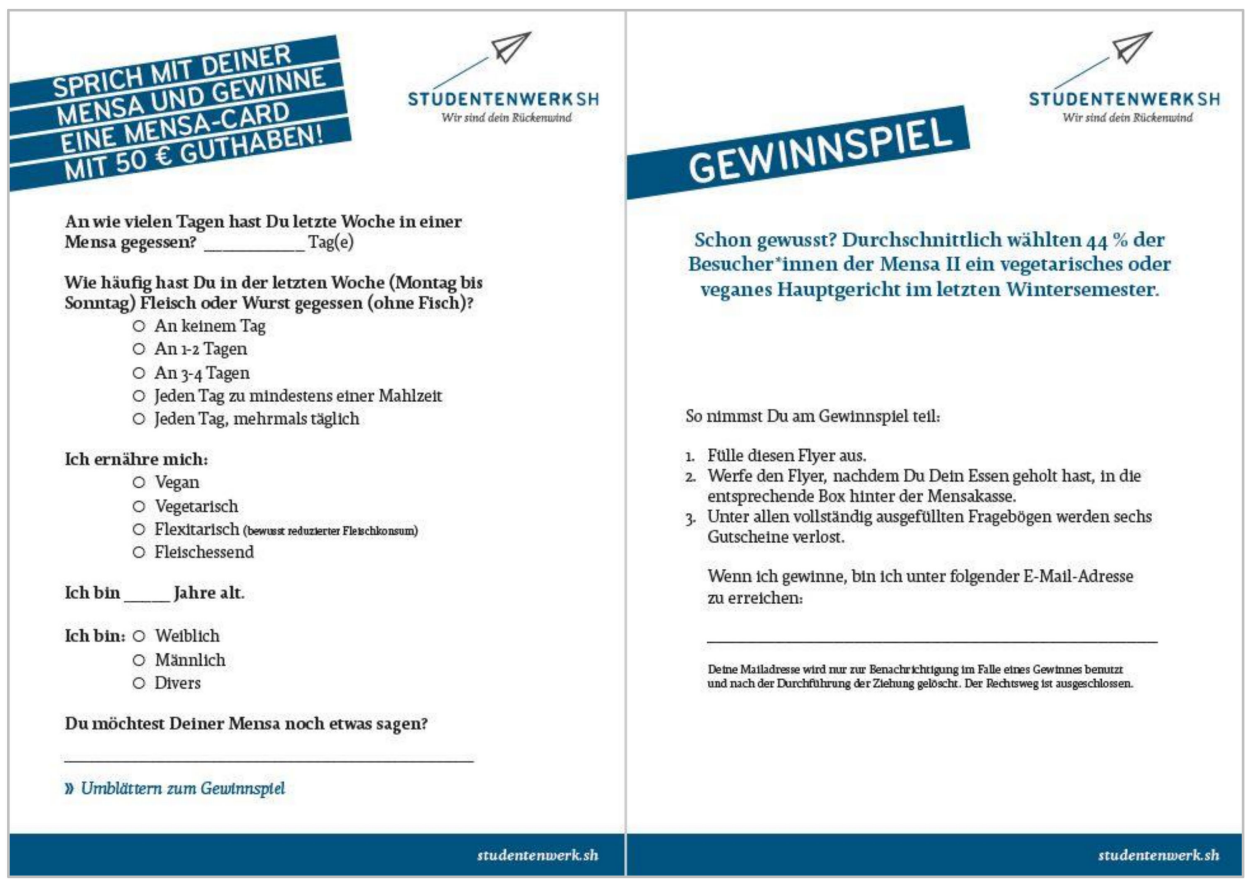

Figure A2. Flyer with questionnaire D2. Left page: “Talk to your canteen and win a $50 €$ —canteen voucher for the canteen"; followed by questions about the amount of visits last week, eating habits, age, and gender. Right page: Norm D2 and lottery instructions. 


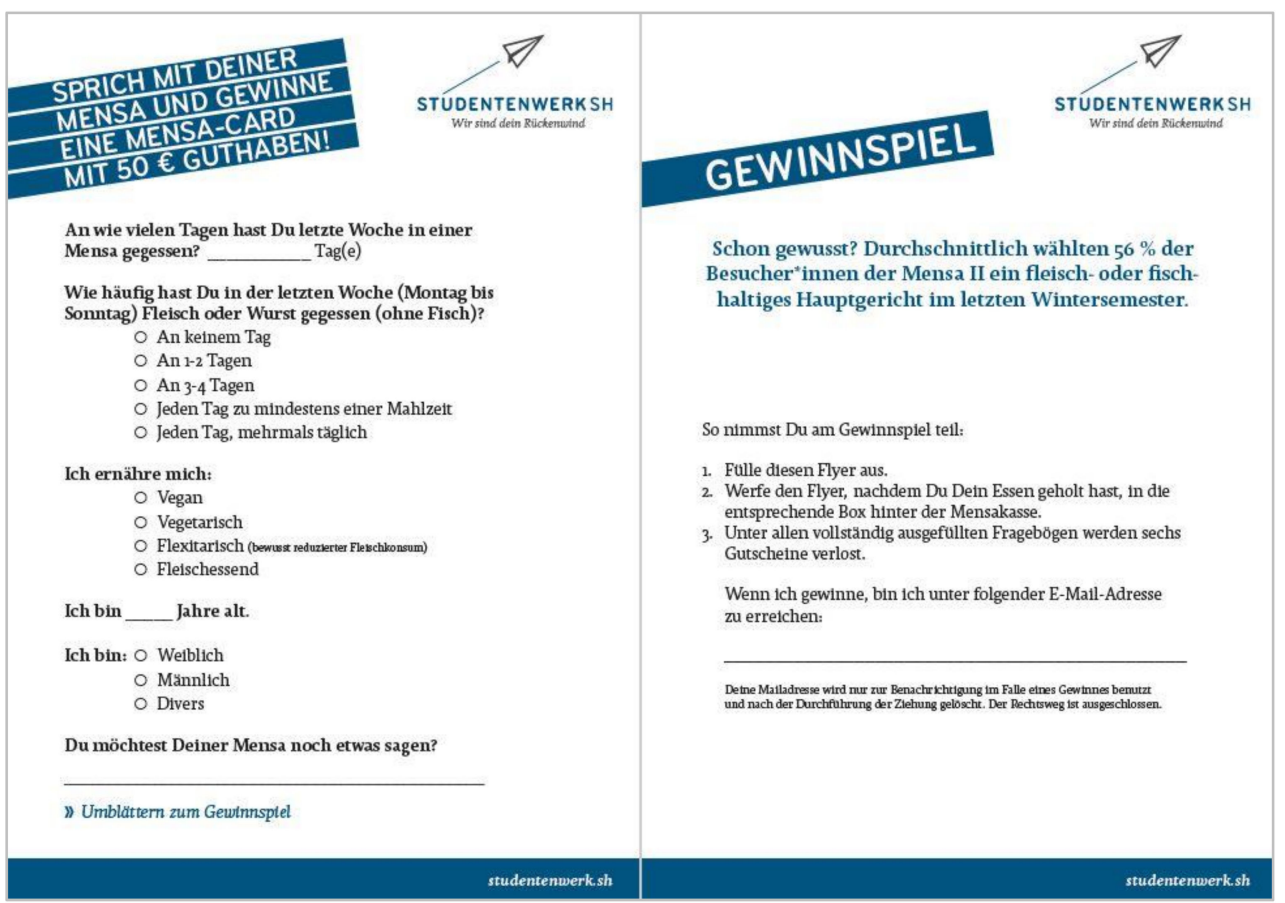

Figure A3. Flyer with questionnaire D3. Left page: “Talk to your canteen and win a $50 €$ - canteen voucher for the canteen"; followed by questions about the amount of visits last week, eating habits, age and gender. Right page: Norm D3 and lottery instructions.

\begin{tabular}{l}
\hline SPRICH MIT DEINER \\
\hline MENSA UND GEWINNE \\
\hline MITE MENSA-CARD
\end{tabular}

Figure A4. Flyer with questionnaire G2. Left page: “Talk to your canteen and win a $50 €$ —canteen voucher for the canteen"; followed by questions about the amount of visits last week, eating habits, age, and gender. Right page: Norm G2 and lottery instructions. 


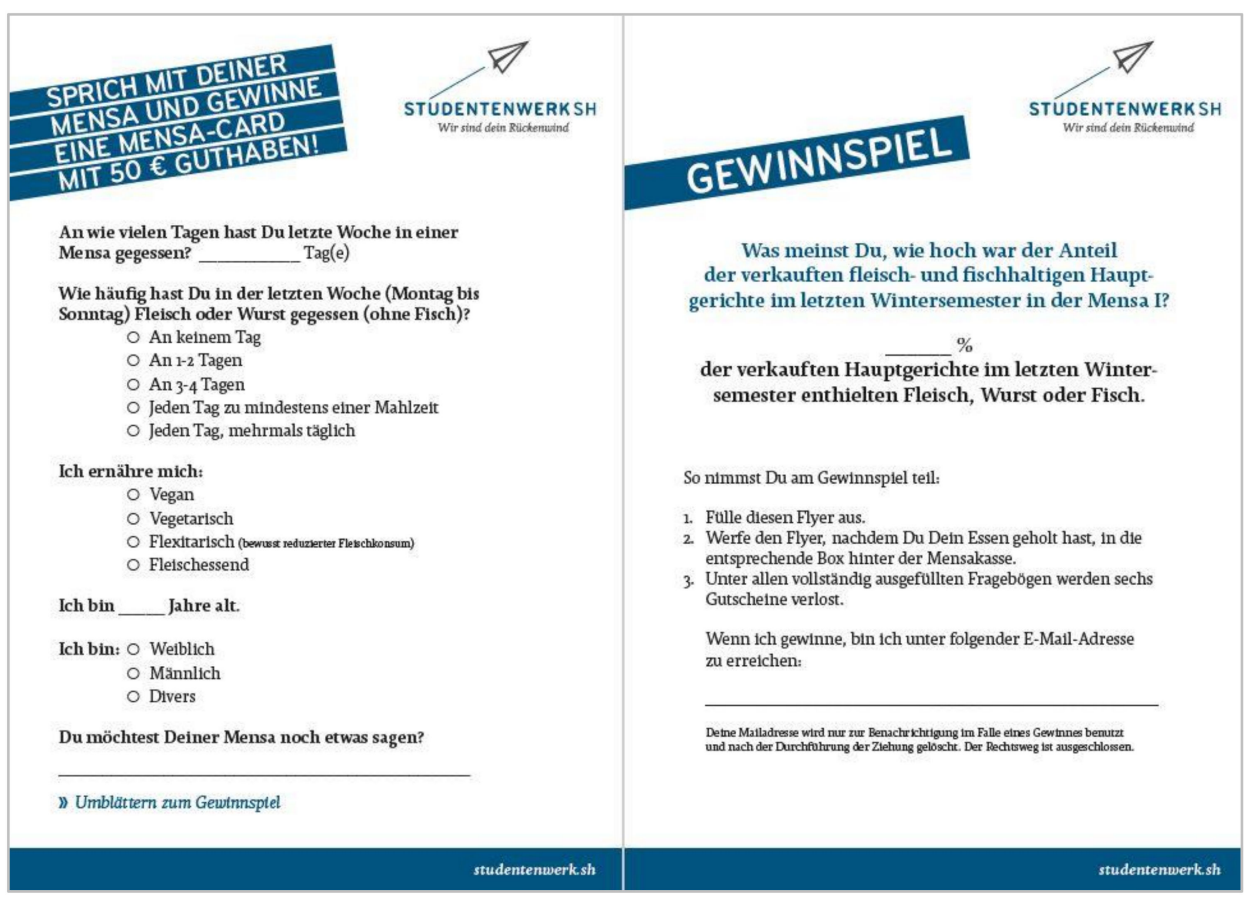

Figure A5. Flyer with questionnaire G3. Left page: "Talk to your canteen and win a 50€—canteen voucher for the canteen"; followed by questions about the amount of visits last week, eating habits, age, and gender. Right page: Norm G3 and lottery instructions.

\section{References}

1. Springmann, M.; Clark, M.; Mason-D’Croz, D.; Wiebe, K.; Bodirsky, B.; Lassaletta, L.; de Vries, W.; Vermeulen, S.; Herrero, M.; Carlson, K.; et al. Options for keeping the food system within environmental limits. Nature 2018, 562, 519-525. [CrossRef]

2. Cordell, D.; White, S. Life's bottleneck: Sustaining the world's phosphorus for a food secure future. Annu. Rev. Environ. Resour. 2014, 39, 161-188. [CrossRef]

3. Newbold, T.; Hudson, L.N.; Hill, S.L.; Contu, S.; Lysenko, I.; Senior, R.A.; Börger, L.; Bennett, D.J.; Choimes, A.; Collen, B.; et al. Global effects of land use on local terrestrial biodiversity. Nature 2015, 520, 45-50. [CrossRef] [PubMed]

4. Vermeulen, S.J.; Campbell, B.M.; Ingram, J.S.I. Climate change and food systems. Annu. Rev. Environ. Resour. 2012, 37, 195-222. [CrossRef]

5. Gerber, P.J.; Steinfeld, H.; Henderson, B.; Mottet, A.; Opio, C.; Dijkman, J.; Falcucci, A.; Tempio, G. Tackling Climate Change Through Livestock-A Global Assessment of Emissions and Mitigation Opportunities; Food and Agriculture Organization of the United Nations (FAO): Rome, Italy, 2013.

6. Springmann, M.; Godfray, H.C.J.; Rayner, M.; Scarborough, P. Analysis and valuation of the health and climate change cobenefits of dietary change. Proc. Natl. Acad. Sci. USA 2016, 113, 4146-4151. [CrossRef]

7. Hallström, E.; Carlsson-Kanyama, A.; Börjesson, P. Environmental impact of dietary change: A systematic review. J. Clean. Prod. 2015, 91, 1-11. [CrossRef]

8. Tilman, D.; Clark, M. Global diets link environmental sustainability and human health. Nature 2014, 515, 518-522. [CrossRef]

9. Westhoek, H.; Lesschen, J.P.; Rood, T.; Wagner, S.; De Marco, A.; Murphy-Bokern, D.; Leip, A.; van Grinsven, H.; Suttong, M.A.; Oenema, O. Food choices, health and environment: Effects of cutting Europe's meat and dairy intake. Glob. Environ. Chang. 2014, 26, 196-205. [CrossRef]

10. Poore, J.; Nemecek, T. Reducing food's environmental impacts through producers and consumers. Science 2018, 360, 987-992. [CrossRef] [PubMed]

11. Willett, W.; Rockström, J.; Loken, B.; Springmann, M.; Lang, T.; Vermeulen, S.; Garnett, T.; Tilman, D.; DeClerck, F.; Wood, A.; et al. Food in the Anthropocene: The EAT-Lancet Commission on healthy diets from sustainable food systems. Lancet 2019, 393, 447-492. [CrossRef]

12. Aleksandrowicz, L.; Green, R.; Joy, E.J.M.; Smith, P.; Haines, A. The Impacts of Dietary Change on Greenhouse Gas Emissions, Land Use, Water Use, and Health: A Systematic Review. PLoS ONE 2016, 11, e0165797. [CrossRef] [PubMed]

13. Bodirsky, B.L.; Dietrich, J.P.; Martinelli, E.; Stenstad, A.; Pradhan, P.; Gabrysch, S.; Popp, A. The ongoing nutrition transition thwarts long-term targets for food security, public health and environmental protection. Sci. Rep. 2020, 10, 19778. [CrossRef] [PubMed]

14. Oyebode, O.; Gordon-Dseagu, V.; Walker, A.; Mindell, J.S. Fruit and vegetable consumption and all-cause, cancer and CVD mortality: Analysis of Health Survey for England data. J. Epidemiol. Community Health 2014, 68, 56-62. [CrossRef] [PubMed] 
15. He, F.J.; Nowson, C.A.; MacGregor, G.A. Fruit and vegetable consumption and stroke: Meta-analysis of cohort studies. Lancet 2006, 367, 320-326. [CrossRef]

16. Carattini, S.; Kallbekken, S.; Orlov, A. How to win public support for a global carbon tax. Nature 2019, 565, 289-291. [CrossRef] [PubMed]

17. Pohjolaina, P.; Tapio, P.; Vinnari, M.; Jokinen, P.; Räsänen, P. Consumer consciousness on meat consumption and the environmentExploring differences. Appetite 2016, 101, 37-45. [CrossRef]

18. Thaler, R.H.; Sunstein, C.R. Nudge; Yale University Press: London, UK, 2008.

19. Lehner, M.; Mont, O.; Heiskanen, E. Nudging-A promising tool for sustainable consumption behavior? J. Clean. Prod. 2016, 134, 166-177. [CrossRef]

20. White, K.; Habib, R.; Hardisty, D.J. How to SHIFT consumer behaviors to be more sustainable: A literature review and guiding framework. J. Mark. 2019, 83, 22-49. [CrossRef]

21. Just, D.R. Smarter lunchrooms: Using behavioral economics to improve meal selection. Choices 2009, 24, 1-7.

22. Wisdom, J.; Downs, J.S.; Loewenstein, G. Promoting Healthy Choices: Information versus Convenience. Am. Econ. J. Appl. Econ. 2010, 2, 164-178. [CrossRef]

23. Ellison, B.; Lusk, J.L.; Davis, D. The Impact of Restaurant Calorie Labels on Food Choice: Results from a Field Experiment. Econ. Inq. 2014, 52, 666-681. [CrossRef]

24. Policastro, P.; Smith, Z.; Chapman, G. Put the healthy item first: Order of ingredient listing influences consumer selection. J. Health Psychol. 2015, 22, 853-863. [CrossRef]

25. Cadario, R.; Chandon, P. Which healthy eating nudges work best? A meta-analysis of field experiments. Mark. Sci. 2020, 39, 465-486. [CrossRef]

26. Gravert, C.; Kurz, V. Nudging à la carte: A field experiment on climate-friendly food choice. Behav. Public Policy 2021, 5, 378-395. Available online: https://www.cambridge.org/core/journals/behavioural-public-policy/article/nudging-a-la-carte-a-fieldexperiment-on-climatefriendly-food-choice/7EAA47F30FEAA990FC4F7EAAF9CAC0C0 (accessed on 3 August 2021). [CrossRef]

27. Brunner, F.; Kurz, V.; Bryngelsson, D.; Hedenus, F. Carbon label at a University Restaurant—Label Implementation and Evaluation. Ecol. Econom. 2018, 146, 658-667. [CrossRef]

28. Kurz, V. Nudging to reduce meat consumption: Immediate and persistent effects of an intervention at a university restaurant. J. Environ. Econ. Manag. 2018, 90, 317-334. [CrossRef]

29. Farrow, K.; Grolleau, G.; Ibanez, L. Social norms and pro-environmental behavior: A review of the evidence. Ecol. Econ. 2017, 140, 1-13. [CrossRef]

30. Richter, I.; Thøgersen, J.; Klöckner, C.A. A social norms intervention going wrong: Boomerang effects from descriptive norms information. Sustainability 2018, 10, 2848. [CrossRef]

31. Gavrilets, S.; Richerson, P.J. Collective action and the evolution of social norm internalization. Proc. Natl. Acad. Sci. USA 2017, 114, 6068-6073. [CrossRef] [PubMed]

32. Goffman, E. Frame Analysis: An Essay on the Organization of Experience; Harper \& Row: New York, NY, USA, 1974.

33. Persson, A. Framing Social Interaction: Continuities and Cracks in Goffman's Frame Analysis; Taylor \& Francis: New York, NY, USA, 2018.

34. Tversky, A.; Kahneman, D. The framing of decisions and the psychology of choice. Science 1981, 211, 453-458. [CrossRef]

35. Levin, I.P.; Gaeth, G.J. How Consumers are Affected by the Framing of Attribute Information Before and After Consuming the Product. J. Consum. Res. 1988, 15, 374-378. [CrossRef]

36. Cialdini, R.B.; Goldstein, N.J. Social influence: Compliance and conformity. Annu. Rev. Psychol. 2004, 55, 591-621. [CrossRef] [PubMed]

37. Goldstein, N.J.; Cialdini, R.B.; Griskevicius, V. A room with a viewpoint: Using social norms to motivate environmental conservation in hotels. J. Consum. Res. 2008, 35, 472-482. [CrossRef]

38. Finnemore, M. National Interests in International Society; Cornell University Press: New York, NY, USA, 1996.

39. Elster, J. Social norms and economic-theory. J. Econ. Perspect. 1989, 3, 99-117. [CrossRef]

40. Bicchieri, C.; Muldoon, R. Social Norms. In The Stanford Encyclopedia of Philosophy; Salta, E.N., Ed.; Stanford University: Stanford, CA, USA, 2011.

41. Young, H.P. The evolution of social norms. Economics 2015, 7, 359-387. [CrossRef]

42. Cialdini, R.B.; Reno, R.R.; Kallgren, C.A. A focus theory of normative conduct: Recycling the concept of norms to reduce littering in public places. J. Pers. Soc. Psychol. 1990, 58, 1015-1026. [CrossRef]

43. Bicchieri, C. The Grammar of Society: The Nature and Dynamics of Social Norms; Cambridge University Press: New York, NY, USA, 2006.

44. Monteith, M.J.; Deneen, N.E.; Tooman, G.D. The effect of social norm activation on the expression of opinions concerning gay men and Blacks. Basic Appl. Soc. Psychol. 1996, 18, 267-288. [CrossRef]

45. Cialdini, R.B.; Demaine, L.J.; Sagarin, B.J.; Barrett, D.W.; Rhoads, K.; Winter, P.L. Managing social norms for persuasive impact. Soc. Influ. 2006, 1, 3-15. [CrossRef]

46. Cialdini, R.B.; Trost, M.R. Social influence: Social norms, conformity, and compliance. In The handbook of Social Psychology, 4th ed.; Gilbert, D.T., Fiske, S.T., Lindzey, G., Eds.; McGraw-Hill: Boston, MA, USA, 1998; Volume 2, pp. 151-192. 
47. Stok, F.M.; Hoffmann, S.; Volkert, D.; Boeing, H.; Ensenauer, R.; Stelmach-Mardas, M.; Kiesswetter, E.; Weber, A.; Rohm, H.; Lien, N.; et al. The DONE framework: Creation, evaluation, and updating of an interdisciplinary, dynamic framework 2.0 of determinants of nutrition and eating. PLoS ONE 2017, 12, e0171077. [CrossRef]

48. Symmank, C.; Mai, R.; Hoffmann, S.; Stok, F.M.; Renner, B.; Lien, N.; Rohm, H. Predictors of food decision making: A systematic interdisciplinary mapping (SIM) review. Appetite 2017, 110, 25-35. [CrossRef]

49. Stok, F.M.; De Ridder, D.T.; De Vet, E.; De Wit, J.B. Don't tell me what I should do, but what others do: The influence of descriptive and injunctive peer norms on fruit consumption in adolescents. Br. J. Health Psychol. 2014, 19, 52-64. [CrossRef]

50. Thomas, J.M.; Ursell, A.; Robinson, E.L.; Aveyard, P.; Jebb, S.A.; Herman, C.P.; Higgs, S. Using a descriptive social norm to increase vegetable selection in workplace restaurant settings. Health Psychol. 2017, 36, 1026. [CrossRef] [PubMed]

51. Salmivaara, L.; Lankoski, L. Promoting Sustainable Consumer Behavior Through the Activation of Injunctive Social Norms: A Field Experiments in 19 Workplace Restaurants. Organ. Environ. 2019, 1-26. Available online: https://journals.sagepub.com/ doi/full/10.1177/1086026619831651 (accessed on 3 August 2021). [CrossRef]

52. McDonald, R.I.; Fielding, K.S.; Louis, W.R. Conflicting norms highlight the need for action. Environ. Behav. 2014, 46, 139-162. [CrossRef]

53. Göckeritz, S.; Schultz, P.W.; Rendon, T.; Cialdini, R.B.; Goldstein, N.J.; Griskevicius, V. Descriptive normative beliefs and conservation behavior: The moderating roles of personal involvement and injunctive normative beliefs. Eur. J. Soc. Psychol. 2010, 40, 514-523. [CrossRef]

54. Hamann, K.R.; Reese, G.; Seewald, D.; Loeschinger, D.C. Affixing the theory of normative conduct (to your mailbox): Injunctive and descriptive norms as predictors of anti-ads sticker use. J. Environ. Psychol. 2015, 44, 1-9. [CrossRef]

55. Cialdini, R.B.; Kallgren, C.A.; Reno, R.R. A Focus Theory of Normative Conduct-A Theoretical Refinement and Reevaluation of the Role of Norms in Human-Behavior. Adv. Exp. Soc. Psychol. 1991, 24, 201-234.

56. Kallgren, C.A.; Reno, R.R.; Cialdini, R.B. A Focus Theory of Normative Conduct: When Norms Do and Do not Affect Behavior. Pers. Soc. Psychol. Bull. 2000, 26, 1002-1012. [CrossRef]

57. Bollinger, B.; Gillingham, K. Peer effects in the diffusion of solar photovoltaic panels. Mark. Sci. 2012, 31, 900-912. [CrossRef]

58. Reese, G.; Loew, K.; Steffgen, G. A towel less: Social norms enhance pro-environmental behavior in hotels. J. Soc. Psychol. 2014, 154, 97-100. [CrossRef]

59. Krupka, E.; Weber, R.A. The focusing and informational effects of norms on pro-social behavior. J. Econ. Psychol. 2009, 30, 307-320. [CrossRef]

60. Bartke, S.; Friedl, A.; Gelhaar, F.; Reh, L. Social comparison nudges-Guessing the norm increases charitable giving. Econ. Lett. 2017, 152, 73-75. [CrossRef]

61. Stok, F.M.; De Ridder, D.T.; De Vet, E.; De Wit, J.B. Minority talks: The influence of descriptive social norms on fruit intake. Psychol. Health 2012, 27, 956-970. [CrossRef]

62. Asch, S.E. Opinions and social pressure. Sci. Am. 1955, 193, 31-35. [CrossRef]

63. Burnkrant, R.E.; Cousineau, A. Informational and normative social influence in buyer behavior. J. Consum. Res. 1975, 2, 206-215. [CrossRef]

64. Demarque, C.; Charalambides, L.; Hilton, D.J.; Waroquier, L. Nudging sustainable consumption: The use of descriptive norms to promote a minority behavior in a realistic online shopping environment. J. Environ. Psychol. 2015, 43, 166-174. [CrossRef]

65. Sherif, M. A study of some social factors in perception. Arch. Psychol. 1935, 27, 1-60.

66. Fischbacher, U.; Gächter, S. Social Preferences, Beliefs, and the Dynamics of Free Riding in Public Goods Experiments. Am. Econ. Rev. 2010, 100, 541-556. [CrossRef]

67. Kouchaki, M. Vicarious moral licensing: The influence of others' past moral actions on moral behavior. J. Pers. Soc. Psychol. 2011, 101, 702. [CrossRef] [PubMed]

68. Perkins, H.W.; Haines, M.P.; Rice, R. Misperceiving the college drinking norm and related problems: A nationwide study of exposure to prevention information, perceived norms and student alcohol misuse. J. Stud. Alcohol Drugs 2005, 66, 470-478. [CrossRef] [PubMed]

69. Turner, J.C. Some current issues on research on social identity and self-categorization theories. In Social Identity: Context, Commitment, Content; Ellemers, N., Spears, R., Doosje, B., Eds.; Blackwell: Oxford, UK, 1999; pp. 6-34.

70. Johnston, K.L.; White, K.M. Binge-drinking: A test of the role of group norms in the theory of planned behaviour. Psychol. Health 2003, 17, 123-158. [CrossRef]

71. Louis, W.; Davies, S.; Smith, J.; Terry, D. Pizza and pop and the student identity: The role of referent group norms in healthy and unhealthy eating. J. Soc. Psychol. 2007, 147, 57-74. [CrossRef]

72. Gneezy, A. Field Experimentation in Marketing Research. J. Mark. Res. 2017, 54, 140-143. [CrossRef]

73. Gordon, B.R.; Zettelmeyer, F.; Bhargava, N.; Chapsky, D. A comparison of approaches to advertising measurement: Evidence from big field experiments at Facebook. Mark. Sci. 2019, 38, 193-225. [CrossRef]

74. Borsari, B.; Carey, K.B. Descriptive and injunctive norms in college drinking: A meta-analytic integration. J. Stud. Alcohol 2003, 64, 331-341. [CrossRef]

75. Perkins, H.W.; Craig, D.W. A successful social norms campaign to reduce alcohol misuse among college student-athletes. J. Stud. Alcohol 2006, 67, 880-889. [CrossRef] [PubMed] 
76. Tangari, A.H.; Bui, M.; Haws, K.L.; Liu, P.J. That's Not so Bad, I'll Eat More! Backfire Effects of Calories-per-serving Information on Snack Consumption. J. Mark. 2019, 83, 133-150. [CrossRef]

77. Clee, M.A.; Wicklund, R.A. Consumer behavior and psychological reactance. J. Consum. Res. 1980, 6, 389-405. [CrossRef]

78. Rhodes, N.; Ralston, R.; Bigsby, E. Teens' Reactance to Anti-Smoking Public Service Announcements: How Norms Set the Stage. J. Health Commun. 2016, 21, 575-582. [CrossRef]

79. Lasarov, W.; Hoffmann, S. Social moral licensing. J. Bus. Ethics 2020, 165, 45-66. [CrossRef]

80. Harrison, G.W.; List, J.A. Field Experiments. J. Econ. Lit. 2004, 42, 1009-1055. [CrossRef]

81. Petty, R.E.; Cacioppo, J.T. The elaboration likelihood model of persuasion. In Communication and Persuasion; Seiter, J.S., Gass, R.H., Eds.; Springer: New York, NY, USA, 1986; pp. 1-24.

82. Mormann, M.M.; Koch, C.; Rangel, A. Consumers can make decisions in as little as a third of a second. Judgement Decis. Mak. 2011, 6, 520-530.

83. Thøgersen, J.; Jørgensen, A.K.; Sandager, S. Consumer decision making regarding a "green" everyday product. Psychol. Mark. 2012, 29, 187-197. [CrossRef]

84. Kristal, A.S.; Whillans, A.V. What we can learn from five naturalistic field experiments that failed to shift commuter behaviour. Nat. Hum. Behav. 2020, 4, 169-176. [CrossRef] [PubMed] 